\title{
UTOPIA QUIXOTESCA DOS DIREITOS HUMANOS
}

\author{
MELINA GIRARDI FACHIN ${ }^{1}$
}

\begin{abstract}
RESUMO: O objetivo do presente artigo é (re)contar o discurso jurídico dos direitos humanos por meio das lentes emancipatórias da literatura através da obra $O$ engenhoso fidalgo Dom Quixote de La Mancha, de Miguel de Cervantes. Objetiva-se traçar um paralelo entre a luta de Quixote e a luta dos e pelos direitos humanos na atualidade, mostrando seus pontos de aproximação, sem a pretensão de esgotálos. A partir desta abertura do direito para a literatura, explorar-se-á o discurso jurídico dos direitos humanos com aporte na narrativa literária de Cervantes. A vocação quixotesca de combate às injustiças, o enfoque nos vulneráveis, a dimensão da alteridade dialógica - todas estas marcadas pela tensão entre a realidade e a idealidade - que sobressaem na obra eleita são pontos comunicantes com os paradoxos e dilemas da concretização dos direitos na contemporaneidade. $\mathrm{O}$ desafio que se coloca, é, a partir de uma outra postura do - e perante o - direito(s), a partir dos diálogos com Quixote, conferir concretude possível aos direitos humanos, descortinando-se, assim, o horizonte da uma utopia possível de transformá-los em uma dimensão palpável da realidade.
\end{abstract}

PALAVRAS-ChaVE: Quixote; direitos humanos; emancipação; utopia.

\section{INTRODUÇÃO}

As crises experimentadas na atualidade - o ocaso da democracia no Brasil; a falência de um sistema global capaz de responder de modo satisfatório à crise humanitária - nos levam a uma necessária avaliação da tradição dos direitos humanos. Esse cenário alarmante denuncia uma conjuntura de direitos humanos insustentável que se faz surda perante o grito dos excluídos.

1 Doutora em Direito Constitucional, com ênfase em direitos humanos, pela Pontifícia Universidade Católica de São Paulo. Pesquisadora visitante da Harvard Law School. Professora da Faculdade de Direito da Universidade Federal do Paraná (UFPR). Advogada. Curitiba, Paraná. CV Lattes: http://lattes.cnpq.br/1368334568714.375. E-mail: melinafachin@gmail.com. 
O hiato entre a enunciação teórica e a prática efetiva em matéria de direitos humanos exprime a necessidade de buscar alternativas compromissadas. Esse balanço pode vir de uma miragem crítica e inovadora que contenha outras possibilidades teóricas, especialmente críticas em relação ao papel do ordenamento na salvaguarda dos direitos humanos e fundamentais. Desponta a literatura como uma dessas possibilidades de análise no campo dos direitos humanos, como emancipação destes frente à racionalidade jurídica tradicional.

O discurso literário é mais diverso, complexo, heterodoxo e imaginativo - o que lhe permite maior plasticidade, sensibilidade e atenção à realidade; ingredientes dos quais o direito precisa para se comprometer com a realidade daqueles a quem pretende tutelar. A literatura oferece ao direito um vasto repertório de observação das relações humanas sociais, bem como traz liberdade ao direito reiteradamente descontruindo os formalismos da estrutura jurídica.

A análise de obras literárias - como $O$ engenhoso Fidalgo Dom Quixote de La Mancha - oferece diferentes perspectivas à interpretação dos direitos humanos, principalmente àquelas comprometidas com a realidade.

O vínculo entre o Direito e a Literatura abrolha da narrativa. A articulação do discurso jurídico com a narrativa literária é apropriada, uma vez que insta a abertura contextualizada do direito. De nada valem normas e regras sem contexto, sem história, sem um fato para lhe atribuir significado. Assim, o recurso à literatura (re)conduz os direitos humanos à dimensão real. (Re)contar os direitos humanos (OST, 2004) a partir da literatura quebra, portanto, a apreensão normativista e clama sua abertura. Isso dá aos direitos a possibilidade de ir além da mera descrição e prescrição, acrescentando narrativa e crítica à sua hermenêutica e aplicação.

A literatura opera uma refundação basilar na concepção jurídica dos direitos. A possibilidade de superação dessa distância prática que guarda o direito tradicional por meio de uma ponte literária que o aproxime dos sujeitos concretos e da justiça material é que torna imprescindível que a esta singela reflexão aporte o conjunto de ideias acima exposto.

O objetivo do presente artigo é (re)contar o discurso jurídico dos direitos humanos por meio das lentes emancipatórias da literatura. Para 
tanto escolhida a obra O engenhoso fidalgo Dom Quixote de La Mancha, de Miguel de Cervantes. Valendo-se da obra literária e de pesquisa bibliográfica, o objetivo é traçar um paralelo entre a luta de Quixote e a luta dos e pelos direitos humanos na atualidade, mostrando seus pontos de convergência a partir do salutar diálogo entre direito e literatura.

\section{QUIXOTE E OS DIREITOS: SUBVERSÃO E EMANCIPAÇÃO}

O engenhoso fidalgo Dom Quixote de La Mancha é uma obra complexa de um autor complexo. Miguel de Cervantes reflete muito sobre o próprio sentido da escrita e dá a ela a direção crítica do mundo ao seu entorno. O tempo presente, os homens presentes e a vida presente são sua matéria, para parafrasear Carlos Drummond de Andrade (1969. p. 14). Sua literatura reflete indubitavelmente as vicissitudes, peculiaridades e idiossincrasias de seus sujeitos, bem como o contexto no qual está inserida.

Obviamente não existe tão-somente uma leitura da obra em questão, sendo este um olhar dentre os muitos. Aliás, a riqueza e destaque da trajetória quixotesca reside justamente aí, como nos alerta José Garcez Ghirardi:

Que Dom Quixote possa ser lido em uma chave marxista, liberal ou feminista, por exemplo, não nos diz que o romance seja mal escrito ou confuso, nem nos insinua que Cervantes não tivesse clareza sobre o que queria dizer. Pelo contrário. Admiramos ainda mais o autor porque seu texto nos permite articular tantas perspectivas diferentes. A sobreposição de sentidos, muitas vezes conflitantes, é vista como uma riqueza desse clássico maravilhoso. Ao contrário do que ocorre com nossas expectativas em relação ao Direito, tendemos a entender que na Literatura as interpretações diferentes são uma virtude, não um problema (Ghirardi, 2016, p. 59).

Emerge daí muito claramente o substrato político muito presente na literatura cervantina e que combina com o sentido inspirador de reformas políticas e jurídicas que a literatura pode ter - nas lições de Morawetz: "Essas produções literárias tendem a moldar as atitudes populares; essas atitudes, por sua vez podem afetar as abordagens legais para os direitos e outras reivindicações das classes menos favorecidas” (Morawetz, 1996. p. 453).

A literatura, sobremaneira aquelas que como a cervantina assumem postura crítica do real, pode ser uma grande força motriz para propor e 
problematizar a alteração dos rumos sociais e jurídicos. No geral, a literatura teve sempre um substrato político presente que inspirou reformas políticas e jurídicas. Victor Hugo foi ao encontro dessa ordem de ideias ao afirmar que "la littérature commence par former le public, après quoi elle fait le peuple. Écrire c'est gouverner" (apud Ost, 2004, p. 17).

Sob a égide do dogmatismo, os efeitos sociais e políticos que abrolham desse diálogo transformador que a literatura pode ter no direito e nos direitos foram, por muito tempo, enclausurados em consonância com uma visão fechada da realidade e também dos direitos - e isso porque, como destaca Ost, "colocou-se a literatura sob tutela para preservar a integridade do dogma" (2004, p. 9).

A literatura como produto humano, tal qual a ciência jurídica, reflete indubitavelmente, em maior ou menor escala, as vicissitudes, peculiaridades e idiossincrasias de seus sujeitos, bem como o contexto no qual está inserida. Segundo bem demonstra Lukács quando diz que "não há composição sem concepção do mundo" (apud Konder, 1980).

A dimensão política, crítica e libertadora da literatura está presente já de início na obra de Cervantes, já que são justamente os livros que perturbaram a ordem e a razão de Alonso Quijano. São os livros que são os culpados pela loucura de Quixote - tanto que a solução apresentada por sua filha e criada era justamente queimá-los. Acreditavam que "De tanto ler, secou seu cérebro". Ao revés, foi justamente as suas leituras que abriram a possibilidade subversiva de emancipar-se e dar vida ao Quixote.

A crítica à dogmática e seu sentido transformador é na obra travestida de loucura, que nada mais é do que a insurgência com a ordem posta e a capacidade de ver além. É aqui que Alonso Quijano e Quixote que distanciam: Era Alonso Quijano, quando tinha "razão"; depois de ter enlouquecido - se é que enlouqueceu -, virou Quixote. Para Saramago (2005), na sua leitura da obra, Quijano apenas estava farto da vida que levava e - ao decidir radicalmente mudar de vida - diz-se louco, porque, assim, tudo lhe é permitido. Declarou-se, assim, - no mais puro ato de sanidade - louco! A loucura assim o é caracterizada porque subverte a ordem estática, dogmática e normativa da vida (Olivo; Lehmann, 2015).

Emerge daí o potencial transformador da literatura: Quixote entrou na imortalidade, ao final volta Quijano para morrer no limitado espaço da 
razão. Sua morte é justamente o retorno à suposta lucidez estéril de imaginação. A loucura é, portanto, aqui apreendida em sua dimensão emancipatória do enclausuramento das formas postas da normatividade racional.

O potencial emancipador da imaginação propiciada pela literatura emerge aqui como elemento central. A Quixote, foi o que lhe preencheu a vida; aos direitos, a imaginação poética pode auxiliar a determinação do seu próprio objeto na medida que desvela os sujeitos, seu sofrimento e pretensões. Nussbaum corrobora com essa ordem de ideias ao atestar que "al imaginar cosas que en verdad no existen, la novela, como ella misma lo manifiesta, no es improductiva, pues ayuda a sus lectores a reconocer su propio mundo y a escoger más reflexivamente" (Nussbaum, 1997. p. 60).

Ainda que exsurjam problemas dessa aproximação - sem dúvida a exacerbada imaginação de Quixote colocou-lhe em circunstâncias complexas, a própria constatação de problemas é benéfica já que passa a ser tomada como uma dimensão constitutiva existente. A saber: "La pratique aura vite fait de re-problématiser les normes ainsi définies: des conflits de devoir apparaîtront, des situations inédites se présenteron qui feront que le decideur renouera avec la sagesse pratique, et parfois le tragique de l'action: nos pas choisir entre le blanc et le noir, mais entre le blanc et le gris, ou pire encore, entre entre le gris et le gris ou le gris et le noir" (Ost, 2004, p. 33)

Se os conflitos são parte da realidade, eles passam a ser parte do direito - não como algo a ser extirpado; como uma doença a ser curada -, mas sim como elemento constitutivo de seu próprio âmago e não um mal em si mesmo. A dimensão conflitual, agonística e dialógica dos direitos humanos permite-se, assim, sair a luz. A tensão política no exercício da democracia em sua radicalidade são, portanto, essenciais à noção de direitos humanos. "Uma abordagem agoni'stica reconhece os limites reais de tais fronteiras e as formas de exclusão que delas decorrem, ao inve's de tentar disfarçá -los sob o vé u da racionalidade e da moralidade”, alerta Chantal Mouffe (2005, p. 22).

A partir dessa abertura do direito para a literatura, explorar-se-á o discurso jurídico dos direitos humanos com aporte na narrativa literária quixotesca de Cervantes. Diversos pontos da engenhosa narrativa de 
Quixote podem ser aproximados do discurso dos direitos humanos. A vocação quixotesca de combate às injustiças, o enfoque nos vulneráveis, a dimensão da alteridade dialógica - todas estas marcadas pela tensão real/ideal que sobressaí na obra e é hoje o grande paradoxo no dilema da concretização dos direitos. O objetivo da presente reflexão é explorar alguns desses pontos sem a pretensão de esgotá-los.

\section{A LUTA PELA (IN)JUSTIÇA}

O móvel da obra e do Quixote é a denúncia das injustiças; o cavaleiro relata que seu dever e destino é reparar as injustiças do mundo: "O dever e destino declarado do cavaleiro da triste figura é reparar as injustiças do mundo”, conta-nos Cervantes. Nesse aspecto, o texto cervantino aproximase muito da vocação contramajoritária dos direitos humanos. São os direitos humanos produzidos a partir da dinâmica social, "em defesa de novas liberdades contra velhos poderes" (Bobbio, 2004. p. 51), frutos de uma "racionalidade de resistência" (Flores, 2009, p. 163).

É nesse influxo que os direitos humanos avultam como um contrapoder, na expressão de Luigi Ferrajoli (2007, p. 346), que marca o processo constante de lutas contra a lei do mais forte. Nas palavras do autor: "Los derechos fundamentales son siempre leyes del más débil frente a la ley del más fuerte, que bien puede ser la ley expresada por sus mismas culturas, incluidas las que conviven en nuestros propios países occidentales: [...] a los oprimidos de las prácticas opresivas de sus culturas" (Ferrajoli, 2007, p. 369).

Essa perspectiva combina com a tônica dos direitos humanos que visam a equilibrar as relações assimétricas de poder como insurreições contra os despotismos, provenientes dos campos público ou privado. No mesmo diapasão, aponta Ronald Dworkin que são esses direitos trunfos poderosos - majoritários, mas, sobretudo, contramajoritários - da luta pela construção de uma sociedade mais inclusiva em que todos estejam sujeitos a igual respeito e consideração. Afiança o autor: "Rights are best understood as trumps over some background justification for political decisions that states a goal for the community as a whole" (Dworkin, 1984, p. 153). 
Justiça, direitos e literatura aqui se encontram. Justiça poética pautadas por direitos doces, na lição de Nussbaum (1997) e Mirreile Delmas Marty (2005).

Por meio dessa racionalidade, o direito passa a enxergar os sujeitos não mais como membros de uma ficção inominada e indiferenciada, destinatária da abstração dos textos legais, mas sim como singularidades próprias e únicas. Isso porque o direito tal qual a literatura narra uma história - a história contada pelos direitos humanos é a história da prevenção ou combate do sofrimento humano. Ao assim narrá-la, "induce al lector a interesarse por los personajes, a participar de sus proyectos, temores e esperanzas, a compartir sus intentos de desentrañar los misterios y perplejidades de sus vidas” (Nussbaum, 1997, p. 59). Ao entrever a concretude do outro, os leitores compreendem também sua própria história e, em exercício de alteridade, convertem-se também em personagens - da mesma maneira que Quijano virou Quixote.

Sobre a conformaçao do discurso do direito como justiça poética, ensina Nussabaum:

Todos somos, en la medida que interactuamos moral y políticamente, proyectores fantasiosos, todos creamos ficciones y metáforas y todos creemos en ellas. Lo cierto es que la escuela "fáctica", que niega experiencia subjetiva a las vacas y caballos - y humanidad a los obreros -, se embarca en la creación de ficciones tanto como los lectores de novelas y los soñadores. Su rotunda negación de la vida y la humanidad exceden, como los asertos de los otros, los límites de la evidencia. Nunca conoceremos con certeza el contenido del corazón de esa forma que percibimos, sólo podemos escoger entre una interpretación generosa y una interpretación mezquina. La visión interna o fantasía, la gran caridad del corazón, alimenta una interpretación generosa del mundo. Esta interpretación, como bien sugieren las novelas, no sólo es más adecuada como explicación de la totalidad de la conducta humana tal como la experimentamos, sino que también es causa de mejores modos de vida (Nussbaum, 1997, p. 60).

A generosidade afetuosa que daí emerge combina com o direito - e direitos - que seja mais doce. Na sua obra, o direito 'suave' (droit mou) ou 'doce' (droit doux) aparece, nas lições de Mireille Delmas-Marty, não como um direito frágil, mas como um direito flexível e, por isso mesmo, durador. No mesmo sentido, a ductibilidade do direito anunciada por Zagrebelsky, que aponta para "una construcción necesariamente no rígida que dé cabida 
a las combinaciones que deriven no ya del derecho constitucional, sino de la política constitucional. Se trata de lo que podría llamarse la instabilidad de las relaciones entre los conceptos" (Zagrebelsky, 2003, p. 17).

É justamente essa porosidade que permite a emancipação pluralista do fenômeno jurídico do normativismo homogêneo e pasteurizante que o segura distante da realidade social que o discurso literário nos permite. Nesse diapasão, afiança Ost: "alors que la littérature libère des possibles, le droit codifié la realité [...] Tel est bien le travail de la littérature: bousculer les conventions, suspendre nous certitudes, libérer des possibles - dégager l'espace ou libérer le temps des utopies créatrices" (Ost, 2004, p. 10).

Associado à defesa das injustiças, Quixote defende o exército mais fraco e luta pelos fatigados, machucados. Esses são os sujeitos dos direitos. Os fatigados, os machucados por quem Quixote luta.

\section{A MARGEM COMO ELEMENTO CENTRAL E O LUGAR D'OUTRO}

É de Bobbio a célebre frase de que a luta pelos direitos humanos é a batalha pelo possível, e não pelo desejável (Bobbio, 2004, p. 24). Nos coloca, adicionalmente, o mesmo autor que onde a proteção dos direitos humanos é mais necessária nem sempre é possível, e onde é possível talvez não seja tão necessária.

O mesmo se passa com os sujeitos desses direitos. Aqueles que mais precisam são muitaz vezes excluídos do próprio discurso de proteção, são aqueles não reconhecidos pelo direito em sua radicalidade. Esses direitos são os reflexos da proteção possível, e não do desejável, dentro dos avanços e recuos dos movimentos sociais, e por isso nascem quando podem e não quando devem, "não todos de uma vez e nem de uma vez por todas" (Bobbio, 2004, p. 25).

É justamente essas figuras que Cervantes privilegia em sua obra - os excluídos são justamente os protagonistas eleitos por ele para estampar o romance de cavalaria protagonizado por Quixote. Seu personagem central, o cavaleiro Sr. Quijano era velho ("beirava os 50"), magro, ossudo de rosto chapado - uma "triste figura". Sua amada, Dulcineia del Toboso, é descrita como feia e fedorenta. Por sua vez seu fiel escudeiro, Sancho Pança, era gordo, que nada vê e nada escuta (não compartilhava da sadia loucura do Quixote, via as coisas estreitamente como eram). Mesmo seu cavalo, 
Rocinante, era, na realidade, um pangaré. Emergem como personagens centrais, os excluídos e vulneráveis que, com Cervantes, ganham protagonismo. $\mathrm{O}$ elemento central para sua caracterizaçao é justamente a não dominância.

De modo inevrso que a literatura de Cervantes, a literalidade normativa dos direitos humanos ainda não se abriu, de modo completo, ao reconhecimento e inclusão dos excluídos. O idioma dos direitos humanos deve ser aquele da alteridade e reciprocidade, nos ensina Nancy Fraser ao incluir a dimensão da política de reconhecimento como um dos critérios balizadores da justiça em sua dimensão substancial.

A marca contemporânea dos direitos humanos nasce atrelada à ética da alteridade: a ver no outro um ser merecedor de igual consideraça $\square$ o e profundo respeito, orientada pela afirmaça $\square$ o universal da dignidade e pela prevença $\square$ o do sofrimento humano. Torna-se, contudo, insuficiente tratar o indivi duo de forma gené rica, geral e abstrata. Faz-se necessá ria a especificaça $\square$ o do sujeito de direito, que passa a ser visto em sua peculiaridade e particularidade. Determinados sujeitos e determinadas violaço $\square$ es exigem uma resposta especi fica e diferenciada. Assim que, ao lado do direito a 'igualdade, surge, també $m$ como direito fundamental, o direito a`diferença com respeito a`diferença e a`diversidade (Piovesan, 2008).

Os processos de busca de igualdade e reconhecimento estão profundamente ligados à ressignificação e à possibilidade emancipatória que os direitos humanos sob essa nova mirada são capazes de gerar. É o que ressalta Fraser: "la justicia exige sistemas sociales que permitan que todos los miembros adultos de la sociedad interactúen unos con otros en pie de igualdad" (Fraser, 2003, p. 107-108).

No que diz respeito a’ proteça $\square$ o dos direitos humanos, as noço $\square$ es de igualdade e de vulnerabilidade esta $\square$ o unidas. $S a \square$ o vulnerá veis aqueles que têm diminui das, por diferentes razo $\square$ es, sua capacidade de enfrentamento e resistência à violaç, $\square$ es de direitos. Essa diminuiça $\square$ o de capacidades está associada a determinada condiça $\square$ o que permite identificar o indivi' duo como membro de um grupo excluído.

Esses sujeitos ainda estão despojados do direito e dos direitos. Verifica-se "o paradoxo como princípio organizador dos direitos humanos" 
(Douzinas, 2009. p. 13), pois "o outro, na singularidade da sua dignidade e vulnerabilidade, permanece exterior ao conceito e à essência” (Douzinas, 2009, p. 367) de humanidade forjada no cenário moderno liberal.

A fundamentação clássica dos direitos humanos comporta apenas um tipo de humano abstrato: o masculino, branco, proprietário, aquele que se enquadra e não resiste ao modelo social e econômico dominante, como bem expressou Costas Douzinas, ao elucidar que:

O homem dos direitos do homem não tem características concretas, exceto pelo livre arbítrio, razão e alma, os esboços nus da humanidade. [...] esse homem é uma abstração sem corpo, cor, gênero ou história. No entanto, o homem concreto que realmente desfrutava dos direitos foi, literalmente, um homem - um homem rico, branco. Cristão, urbano. Ele condensou a dignidade abstrata da humanidade e dos privilégios dos poderosos (Douzinas, 2009, p. 14.)

Os direitos fundados na tradição moderna burguesa, ainda perpetuada na contemporaneidade, não alcançam a todos, em verdade, excluem a maior parte dos seres humanos: "A história nos ensinou que não há nada sagrado em qualquer definição de humanidade e nada eterno sobre o seu alcance" (Douzinas, 2009, p. 14).

Ver o outro e considerá-lo na sua dimensão peculiar implica o exercício de alteridade e tolerância que é o reconhecimento do outro e clama, portanto, pelo diálogo como elemento constitutivo indissociável da noção de direitos humanos. Essa perspectiva dialógica também se faz presente no clássico da literatura.

A obra é um amplo diálogo entre um intelectual, Quixote, e um analfabeto, Sancho Pança, nas discussões das questões fundamentais da vida. Somos sempre em relação ao outro seres relacionais, e os direitos nascem dessa relação. Reforça a lição de Charles Taylor: "This crucial feature of human life is its fundamentally dialogical character" (Taylor, 1994. p. 7).

Assim, os direitos não devem ser considerados exclusivamente como qualidade inata e abstrata do indivíduo insularmente considerado, na medida em que possuem um sentido cultural-relacional-social, sendo fruto da interação mútua. Os direitos são, portanto, um exercício de alteridade, na medida em que são um chamado à abertura ao outro, como fizeram Quixote e Sancho. 
A dimensão dialógica deve ser compreendida como interação conjunta, um ato de doação linguística de um para com o outro, quando os indivíduos se põem no/pelo/com o Outro (Levinas, 2009, p. 50). Abrindose para a heterogeneidade e pluralidade que a dialogicidade permite, a ação comunicativa entre dois sujeitos reconhecidos reciprocamente como capazes de comunicar faz-se mister para a intercessão - ou seja, uma cessão mútua.

Nós nos tornamos sujeitos e definimos nossa identidade sempre a partir e na relação com os outros. Por isso mesmo o livro acaba quando Quixote acaba de dialogar, volta ao silêncio e compartilha com os céticos (barbeiro, padre...) - acaba, portanto, a perseverança - torna a realidade e morre a utopia.

Além da dualidade eu/outro que marca a obra e também o diálogo dos direitos humanos, há binômio central da reflexão quixotesca - poderse-ia dizer que constitui inclusive o mote da obra: real/sonho.

\section{A REALIDADE SONHADA}

A dificuldade da dissociação do que é o imaginado - o sonho - e o real é o traço instigante eleito para explorar as aproximações da batalha quixotesca dos direitos humanos na contemporaneidade. Há na obra de Cervantes uma dificuldade de dissociação entre o real e o sonho. Na célebre passagem do capítulo sétimo acerca dos moinhos de vento, essa perspectiva avulta com máxima força.

Quixote se depara com pouco mais de trinta gigantes, e é esclarecido pelo fiel escudeiro que não passam de moinhos de vento. Não convencido, o cavaleiro avança contra um dos moinhos enquanto grita para as criaturas covardes não fugirem. Quixote se choca contra uma de suas pás, que o derruba junto com seu cavalo Rocinante.

Ao ser novamente alertado por Sancho, Quixote manda o amigo se calar, lhe explicando que as "coisas da guerra, mais que as outras, estão sujeitas a mudança contínua”. Nesse caso, segundo ele, o sábio Frestão transformou os gigantes em moinhos para tirar a glória de sua batalha vencida.

Nesse aspecto mais uma ponte com os direitos humanos: sua contínua mutabilidade. Os direitos são categorias históricas e contextuais. 
Não nascem quando devem, mas sim como podem nascer - são frutos dos avanços e recuos possíveis mergulhados no contexto onde estão inseridos (Bobbio, 2004). A mudança contínua dos direitos opera-se no tempo e no espaço. Texto e contexto assim se entrelaçam (Flores, 2009). Ora os direitos são gigantes poderosos, ora são totens estáticos tais quais os moinhos.

A dimensão importante que aqui se abre e que fica muito explicitada na metáfora do moinho é a luta do sonho em relação à realidade. Lutar contra os moinhos de vento é a (des)construção da realidade a partir do sonho/loucura de Quixote. O paradoxo já principia pelo próprio título do capítulo: "Del buen suceso que el valeroso don Quijote tuvo en la espantable y jamás imaginada aventura de los molinos de viento, con otros sucesos dignos de felice recordación". Ou seja, a derrota é entrevista como uma expedição bem-sucedida. A razão cede à loucura.

Resta saber se nossa batalha contemporânea dos/pelos direitos é partir contra os moinhos de vento estabelecidos. Vivemos paradoxalmente o triunfo do discurso normativo dos direitos com sua extensão universal, por um lado, mas, por outro, vivemos uma crise humanitária sem precedentes em termos de descartabilidade dos direitos e de seus sujeitos.

De um lado, a normatividade posta. O texto constitucional brasileiro no artigo $5^{\circ}$, parágrafo primeiro, confere posição de destaque aos direitos fundamentais quando afirma que "as normas definidoras de direitos e garantias fundamentais têm aplicação imediata”. Nada mais agridoce que nosso sentimento em relação aos direitos já que, para muitos, ainda carece que a vontade de constituição se faça presente, exercendo, perante a realidade, sua força normativa. A distância entre o texto constitucional e a eficácia social da norma, entendida como a efetiva obediência das normas na faticidade social (efetivação), faz com que, muitas vezes, a luta pelos direitos seja exatamente aquela travada por Quixote contra os moinhos.

É justamente esse arco entre a aplicabilidade da norma in abstrato e o resultado decorrente da sua efetiva aplicabilidade que deverá ser traçado para superar o fosso abissal entre a prática e a teoria dos direitos humanos. Ainda que pareça lutar em vão, a trajetória do engenhoso fidalgo nos prova equivocados.

A latente decepção com (e do) constitucionalismo pátrio está vinculada à carência de efetivação das normas constitucionais, pois, em 
análise regressiva, nota-se a ausência de sintonia dos preceitos constitucionais, ou ao menos de seu amoldamento prático, à realidade social. Há um nítido "contraste entre as declarações solenes e sua consecução, entre a grandiosidade das promessas e a miséria das realizações" já que o "crescimento moral não se mensura pelas palavras, mas pelos fatos. De boas intenções o inferno está cheio" (Bobbio, 2004, p. 64).

Entre os gigantes e os moinhos está a luta contemporânea pelos direitos. A previsão normativa e o estatuto jurídico dos direitos pendulam entre a realidade dos moinhos de vento e a idealidade dos gigantes fomentando um sentimento de frustração constitucional de um vir-a-ser (seja gigante, seja moinho) que parece não chegar.

Os direitos nascem com a pretensão gigantesca de empoderar os sujeitos, todavia, os tolhem com suas próprias pás estáticas. Foram transformados pelos "vilões" em artifícios de sua própria violação. É esse o processo de inversão da proteção na qual o próprio discurso dos direitos é utilizado para justificar a sua violação.

Os fundamentos dos direitos, ainda capturados pela tradição liberal, acabam por implicar a naturalização de um processo que os leva à clausura, impedindo sua realizabilidade prática, a não ser para aqueles que dele já usufruem. É necessário buscar, portanto, alternativas teóricas que escapem desse lugar comum.

Aqui não se trata apenas de um problema de verificação prática, mas sim de fundamento. Portanto, a célebre ideia de Bobbio (2004) - para quem o problema dos direitos humanos não é mais de justificá-los, e sim de implementá-los, não nos serve. Justamente porque para termos um modelo de direitos comprometido com a prática é necessária uma alternativa teórica que recuse o naturalismo abstrato na base dos direitos e que busque uma perspectiva histórica e contextualizada da realidade dos direitos humano. Nas palavras de Flores:

Cuando se dice que o principal problema dos direitos é de aplicaçao se está dizendo que o problema não é normativo, legislativo, mas da necessidade de sua implementação. Mas a implementação da legislaçao não é um problema só jurídico, mas de poder social, de estructuras y relaciones de fuerzas que impiden la realización de derechos consagrados para determinados grupos sociales (en este caso las mayorías de Ia población 
mundial). Tal afirmación es profundamente ideológica, pues al decir: la institución está bien, el problema es de aplicación oculta precisamente el problema que tratamos de mostrar: que Ia principal causa de la violación de los derechos humanos en el mundo de hoy no es producto de un poder despótico que rechaza la instituición derechos humanos, sino de un sistema democrático de derecho que lo consagra y se declara además su "inventor" (Flores, 2000, p. 187).

Como na batalha de Quixote, a tensão entre realidade e idealidade é inerente ao próprio sistema jurídico, e, portanto, aos direitos. Todavia, a tensão entre o ideal e o real não deve servir de subterfúgio para a conformação com a atual aplicação prática dos direitos humanos e fundamentais. Assim, devemos ter percepção dos direitos como reflexão prática e rediviva no cotidiano de seus operadores, na tentativa de mediar a idealidade utópica quixotesca e a dura realidade de Sancho Pança.

\section{CONCLUSÃO}

Da tensão entre o ideal e o real emerge a necessidade de manter acesa a utopia. É inclusive esse sentido prospectivo que nos impulsiona a ir adiante, um passo além, sempre em busca da utopia do amanhã, conforme nos ensina Eduardo Galeano, figurando no horizonte próximo, porém, inatingível. Nesse influxo mais pragmático busca-se a utopia concreta, do amanhã (Ramonet, 2005).

Quando Quixote cavalga em direção aos moinhos de vento, ele cai e se arrebenta - tomba, mas prossegue com a crença -, na perseverança de que poderia vencer os obstáculos, ainda que gigantescos. Mais uma vez aqui o liame com a teoria dos direitos.

Os direitos humanos são, na sua face contemporânea, a história da perseverança. Surgem justamente da sua negação. Foi o rompimento da ideia de direitos que nos legou direitos no pós-guerra. Da rutura, surgiu a proteção. Os direitos tornaram-se, assim, "o grito do oprimido, do explorado, do despossuído, um tipo de direito imaginário ou excepcional para aqueles que não têm nada mais em que se apoiar" (Douzinas, 2009, p. 157). Destarte, é importante buscar alternativas que objetivem conferir-lhes concretude, ainda que utópica.

Tem-se, assim, a utopia, como um projeto, projetando uma proposição: se concretiza quando há ação voltada ao querer mudar. Essa 
ação política, de inconformidade com o dado, com o aparentemente imodificável, deve ser eminentemente contestadora e contextualizada, nos termos preconizados pela teoria crítica dos direitos humanos. É preciso apreender os direitos sob essa perspectiva crítica e ressignificar os seus fundamentos e conteúdo a partir dos seres humanos de carne osso.

Zizek elucida como o pensamento utópico também se aproxima da abertura que a literatura proporciona, já que "sempre esteve repleto de imagens e reminiscências populares reprimidas, sonhos e histórias não contados, lembranças modestas e afetos emocionais projetados em um futuro adorável". Nesse sentido, a utopia dos direitos humanos é transformadora da própria forma de se pensar o direito e os direitos, prossegue o autor:

Os direitos humanos podem preencher o não-lugar da utopia pós-moderna: eles produzem uma poderosa energia política e moral, ao contrário de qualquer outra ideologia; eles extraem suas forças de memórias passadas e esperanças futuras; sua promessa existe, oculta além de convenções, tratados e declarações, em uma variedade de formas culturais inconspícuas. Os direitos humanos, fundados como estão no frágil sentido de identidade pessoal e na esperança - impossível - de integridade social, conectam o individual e o coletivo. Como todas as utopias, eles negam o presente em nome do futuro, o que significa que, paradoxalmente, eles negam os direitos das leis e dos Estados em nome das humanidades plurais ainda por vir (Douzinas, 2009, p. 348).

A utopia pode vir a ser concretizada. Os direitos podem ser realidade. É preciso, todavia, outra postura perante o direito e o mundo para que isso ocorra. A partir da interlocução com o imaginário literário quixotesco e a abertura que esse propicia, é possível construir uma teoria crítica dos direitos humanos pautada numa postura crítica, periférica, dialógica e utópica. Como nos ensina Antônio José Avelãs Nunes:

As mudanças necessárias não acontecem só porque nós acreditamos que é possível um mundo melhor. Essas mudanças hão de verificar-se como resultado das leis de movimento das sociedades humanas, e todos sabemos também que o voluntarismo e as boas intenções nunca foram o motor da história. Mas, a consciência disto mesmo não tem que matar nosso direito à utopia e nosso direito ao sonho. Porque a utopia ajuda a fazer o caminho. Porque sonhar é preciso, porque o sonho comanda a vida (2003, p. 123). 
Ainda que mantendo aceso o seu sentido prospectivo, a ordem protetiva dos direitos humanos precisa aterrissar na realidade como utopia tangível àqueles que dele necessitam uma resposta urgente. $\mathrm{O}$ direito não pode furtar-se a este compromisso prático de celebração dos direitos humanos, essenciais a uma existência minimamente digna, ainda desconhecida por uma expressiva parcela da população do globo.

\section{REFERÊNCIAS}

ANDRADE, Carlos Drummond de. Mãos dadas. In: BARATA, M. S. Canto melhor. Rio de Janeiro: Paz e Terra, 1969.

AVELÃS NUNES, J. A. Neoliberalismo e direitos humanos. Rio de Janeiro: Renovar, 2003.

CERVANTES, Miguel de. O engenhoso fidalgo Dom Quixote de La Mancha. São Paulo: 34, 2010.

DELMAS-MARTY, Mireille. A imprecisão do direito: do código penal aos direitos humanos. Tradução de Denise Radanovic Vieira. São Paulo: Manole, 2005.

DOUZINAS, Costas. O fim dos direitos humanos. São Leopoldo: Unisinos, 2009.

DWORKIN, Ronald. Rights as trumps. In: WALDRON, Jeremy. Theories of Rights. Oxford: Oxford University, 1984.

FACHIN, Melina Girardi. Direitos humanos e fundamentais: do discurso à prática efetiva: um olhar por meio da literatura. Porto Alegre: Nuria Fabris, 2007.

FERRAJOLI, Luigi. Los Fundamentos de los Derechos Fundamentales. Debate con Luca Baccelli, Michelangero Bovero, Ricardo Guastii, Mario Jori, Anna Pintore, Ermano Vitale y Danilo Zolo. Edición de Antonio de Cabo y Gerardo Pisarello. 3.ed. Madrid: Editorial Trotta, 2007.

FLORES, Joaquín Herrera. El Vuelo de Anteo: derechos humanos y crítica de la razón liberal. Bilbao: Desclée, 2000.

FLORES, Joaquín Herrera. A (re)invenção dos direitos humanos. Florianópolis: Boiteux, 2009.

FRASER, Nancy; HONNETH, Axel. Redistribution or Recognition?: A political-philosophical exchange. London: Verso, 2003.

GHIRARDI, José Garcez. O teatro, a consciência do rei: o papel da literatura na formação democrática do jurista. Anamorphosis - Revista Internacional de Direito e Literatura, v. 2, n. 1, p. 53-67, janeiro-junho 2016. doi: $10.21119 /$ anamps.21.53-67

KONDER, L. Lukács. Porto Alegre: L\&PM, 1980.

LEVINAS, Emmanuel. O humanismo do outro homem. Petrópolis: Vozes, 2009. 
MORAWETZ, Thomas. Law and Literature. In. PATTERSON. D. A companion to philosophy of law and legal theory. Cambridge: Blackwell, 1996.

MOUFFE, Chantal. Por um modelo agonístico de democracia. Revista de Sociologia e Política, n. 25, p. 11-23, nov. 2005. Disponível em: $<$ http://www.scielo.br/pdf/rsocp/n25/31108.pdf $>$. Acesso em: 2 maio 2017.

NUSSBAUM, Marta. Justicia poética. Santiago do Chile: Andrés Bello, 1997.

OLIVO, Luis Carlos Cancellier de; LEHMANN, Leonardo Henrique Marques. Dimensão jurídica da loucura e modelos de atenção à saúde mental em Dom Quixote. Anamorphosis - Revista Internacional de Direito $e$ Literatura, v. 1, n. 1, p. 99-120, janeiro-junho 2015. doi: 10.21119/anamps.11.99-120

OST, François. Raconter la loi. Paris: Odile Jacob, 2004.

PIOVESAN, Flávia; SILVA, Roberto B. Dias da. Igualdade e diferença: o direito à livre orientação sexual na Corte Européia de Direitos Humanos e no Judiciário brasileiro. In VIEIRA, José Ribas (Org.). $2 O$ da Constituição cidadã de 1988: efetivação ou impasse institucional? Rio de Janeiro: Forense, 2008. p. 341-367.

RAMONET, I. Quixote hoje: utopia e política. In: IV FÓRUM SOCIAL MUNDIAL. Porto Alegre, jan. 2005.

SARAMAGO, José. Quixote hoje: utopia e política. In: IV FÓRUM SOCIAL MUNDIAL. Porto Alegre, jan. 2005.

SIQUEIRA, Dirceu Pereira; PICCIRILLO, Miguel Belinati. Direitos fundamentais: a evolução histórica dos direitos humanos, um longo caminho. Âmbito Jurídico, Rio Grande, XII, n. 61, fev. 2009. Disponível em:

$<$ http://www.ambitojuridico.com.br/site/index.php?n link=revista artigos leitura\&artigo id= 5414>. Acesso em: 2 maio 2017.

STRECK, Lenio L. Hermenêutica jurídica e $(m)$ crise. Porto Alegre: Livraria do Advogado, 1999.

TAYLOR, Charles. Multiculturalism: examining the Politics of Recognition. Princeton: Princeton University Press, 1994.

ZAGREBELSKY, Gustavo. El derecho dúctil: Ley, derechos, justicia. Tradução de Marina Gascón. 3. ed. Madrid: Trotta, 2003.

ZIZEK, Slavoj. Against Human Rights. New Left Review, London, n. 34, p. 115-131, July/August 2005. Disponível em: <https://newleftreview.org/II/34>. Acesso em: 2 maio 2017.

Idioma original: Português

Recebido: 14/05/17

Aceito: 18/05/17 